$\xi=$

\title{
Divided square difference cordial labeling of some special graphs
}

\author{
A. Alfred Leo ${ }^{1 *}$, R.Vikramaprasad ${ }^{2}$ \\ ${ }^{I}$ Research Scholar, Research and Development centre, Bharathiar University, Coimbatore-641046, Tamil Nadu, India \\ ${ }^{2}$ Assistant Professor, Department of Mathematics, Government Arts College, Salem-636007,Tamil Nadu, India \\ *Corresponding authorE-mail:lee.ancy1@gmail.com
}

\begin{abstract}
\section{Introduction}

For basic notation and terminology in graph theory we refer to Bondy and Murty [2], F. Harary [7] and Rosen Kenneth.H [10] while for number theory we refer Burton [4].Most graph labeling methods were introduced by Rosa [9] in 1967. A dynamic survey on different graph labeling along with an extensive bibliography was found in Gallian [6]. The concept of cordial labeling was introduced by Cahit [3]. Dhavaseelan et.al [5] introduced the concept of even sum cordial labeling graphs. The concept of divisor cordial labeling was introduced by P. Lawrence Rozario Raj and R. Valli [8]. Also further results on divisor cordial labeling was given by S.K.Vaidya and N.H.Shah[11]. Alfred Leo et.al [1] introduced the concept of divided square difference cordial labeling graphs. In this paper, the concepts of divided square difference cordial labeling behavior of jewel graph, $\mathrm{C}_{n-2}+\mathrm{K}_{2}$, Wheel graph, Helm graph, Flower graph, $\mathrm{P}_{\mathrm{n}}+\overline{\mathrm{K}_{\mathrm{m}}}, \overline{\mathrm{K}_{\mathrm{m}}} \cup \mathrm{P}_{\mathrm{n}}+2 \mathrm{~K}_{1}$ and Bistar are introduced
\end{abstract}

In this article, we have introduced the concepts of divided square difference cordial labeling behavior of some special graphs called Jewel graph, $C_{n-2}+K_{2}$, Wheel graph, Helm graph, Flower graph, $P_{n}+\overline{K_{m}}, \overline{K_{m}} \cup P_{n}+2 K_{1}$ and Bistar.

Keywords: Bistar; $C_{n-2}+K_{2}$; Flower Graph; Helm Graph; Jewel Graph; $\overline{K_{m}} \cup P_{n}+2 K_{1} ; P_{n}+\overline{K_{m}}$; Wheel Graph.

\section{Preliminaries}

Definition 2.1:[6]The Graph labeling is an assignment of numbers to the edges or vertices or both subject to certain condition(s). If the domain of the mapping is the set of vertices (edges), then the labeling is called a vertex (edge) labeling.

Definition 2.2:[6]A mapping $f: V(G) \rightarrow\{0,1\}$ is called binary vertex labeling of $G$ and $f(V)$ is called the label of the vertex $v$ of $G$ under $f$.

The concept of cordial labeling was introduced by Cahit [3].

Definition 2.3:[3]A binary vertex labeling $f$ of a graph $G$ is called a Cordial labeling if $\left|v_{f}(0)-v_{f}(1)\right| \leq 1$ and $\left|e_{f}(0)-e_{f}(1)\right| \leq 1$. A graph $G$ is cordial if it admits cordial labeling.

Definition 2.4:[1]Let $G=(V, E)$ be a simple graph and $f: V \rightarrow$ $\{1,2,3, \ldots|V|\}$ be bijection. For each edge $u v$, assign the label 1 if $\left|\frac{(f(u))^{2}-(f(v))^{2}}{f(u)-f(v)}\right|$ is odd and the label 0 otherwise. $f$ is called divided square difference cordial labeling if $\left|e_{f}(0)-e_{f}(1)\right| \leq 1$, where $e_{f}(1)$ ande $_{f}(0)$ denote the number of edges labeled with 1 and not labeled with 1 respectively.

A graph $G$ is called divided square difference cordial if it admits divided square difference cordial labeling.

Definition 2.5:[10]A Wheel graph $W_{n}$ is a graph formed by connecting a single universal vertex to all vertices of a cycle. A Wheel graph with $n$ vertices can also be defined as the 1-skeleton of an n-1 gonal pyramid.

Definition 2.6:[5]The Helm graph $H_{n}$ is the graph obtained from a wheel graph $W_{n}$ by adjoining a pendent edge at each node of the cycle.

Definition 2.7:[5]The Flower graph $\mathrm{Fl}_{n}$ is the graph obtained from the Helm graph $H_{n}$ by joining each pendent vertex to apex of the Helm $H_{n}$.

Definition 2.8:[5]Bistar $B_{m, m}$ is the graph obtained by joining the apex vertices of two copies of star $K_{1, n}$.

\section{Proposition 2.9 [1]}

1) Any path $P_{n}$ is a divided square difference cordial graph.

2) Any cycle $C_{n}$ is a divided square difference cordial graphexcept $n=6,6+d, 6+2 d, \ldots$ whered $=4$.

3) The Star graph $K_{1, n}$ is a divided square difference cordial graph.

\section{Main result}

Proposition 3.1

The Jewel graph is a divided square difference cordial graph.

Proof

Let $\mathrm{G}$ be a Jewel graph.

The jewel graph can be constructed by taking 
$\mathrm{E}(\mathrm{G})=\left\{\mathrm{ux}, \mathrm{xy}, \mathrm{uv}, \mathrm{vy}, \mathrm{xu}_{\mathrm{i}}, \mathrm{vu}_{\mathrm{i}}, 1 \leq \mathrm{i} \leq \mathrm{n}\right\}$.

In this graph, $|V(G)|=n+4$ and $|E(G)|=2 n+4$.

Now we can label the graph by defining a map $\mathrm{f:} \mathrm{V}(\mathrm{G}) \rightarrow\{1,2, \ldots, \mathrm{n}+4\}$ and assign the label values as $\mathrm{f}(\mathrm{u})=1, \mathrm{f}(\mathrm{x})=2, \mathrm{f}(\mathrm{y})=3, \mathrm{f}(\mathrm{v})=\mathrm{p}$ where $\mathrm{p}$ is the largest prime number and $\mathrm{p} \leq \mathrm{n}+4$. Also we can label the vertices $\mathrm{u}_{1}, \mathrm{u}_{2}, \ldots, \mathrm{u}_{\mathrm{n}}$ with labels $4,5,6 \ldots, \mathrm{n}+4$ other than $\mathrm{p}$.

Then we get $\mathrm{e}_{\mathrm{f}}(0)=\mathrm{e}_{\mathrm{f}}(1)$.

Thus $\left|\mathrm{e}_{\mathrm{f}}(0)-\mathrm{e}_{\mathrm{f}}(1)\right| \leq 1$.

Hence $\mathrm{G}$ is a divided square difference cordial graph.

Example 3.2

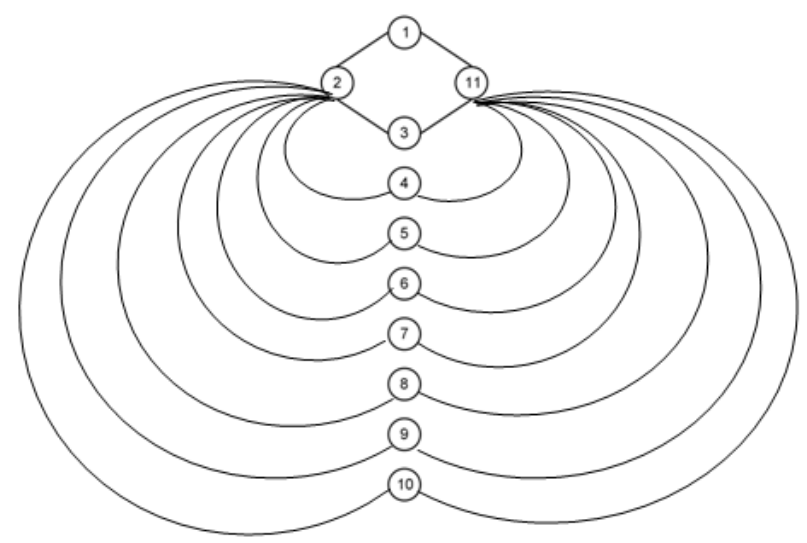

Fig. 1: Jewel Graph When $n=7$.

\section{Proposition 3.3}

The graph $\mathrm{C}_{\mathrm{n}-2}+\mathrm{K}_{2}$ is a divided square difference cordial graph except for $n-2=6,6+d, 6+2 d, \ldots$ where $d=4$.

\section{Proof}

Let $\mathrm{G}$ be a graph $\mathrm{C}_{\mathrm{n}-2}+\mathrm{K}_{2}$.

Let $v_{1}, v_{2}, \ldots, v_{n-2}$ are the vertices of $C_{n-2}$ and $v_{n-1}, v_{n}$ are the vertices of $K_{2}$. Construct the graph $C_{n-2}+K_{2}$.

Define a map $\mathrm{f:} \mathrm{V}(\mathrm{G}) \rightarrow\{1,2, \ldots, \mathrm{n}\}$ as follows.

First we can label the cycle $\mathrm{C}_{\mathrm{n}-2}$ by Proposition 2.9.

Then label $\mathrm{K}_{2}$ by takingf $\left(\mathrm{v}_{\mathrm{n}-1}\right)=\mathrm{n}-1, \mathrm{f}\left(\mathrm{v}_{\mathrm{n}}\right)=\mathrm{n}$.

Then we get $\left|\mathrm{e}_{\mathrm{f}}(0)-\mathrm{e}_{\mathrm{f}}(1)\right| \leq 1$.

Hence $\mathrm{G}$ is a divided square difference cordial graph.

\section{Example 3.4}

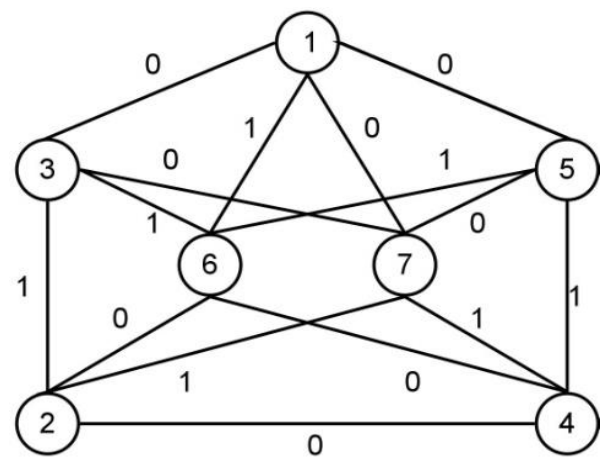

Fig. 2: Graph $\mathrm{C}_{5}+\mathrm{K}_{2}$.

\section{Proposition 3.5}

The Wheel graph $\mathrm{W}_{\mathrm{n}}$ is a divided square difference cordial graph except for $n=6,6+d, 6+2 d, \ldots$ where $d=4$.

\section{Proof}

Let $\mathrm{G}$ be a Wheel graph $\mathrm{W}_{\mathrm{n}}$. Let $\mathrm{u}, \mathrm{v}_{1}, \mathrm{v}_{2}, \ldots, \mathrm{v}_{\mathrm{n}}$ are the vertices of $\mathrm{W}_{\mathrm{n}}$. Here $\mathrm{u}$ is the apex vertex. In this graph, $|\mathrm{V}(\mathrm{G})|=\mathrm{n}+1$ and $|\mathrm{E}(\mathrm{G})|=2 \mathrm{n}$.

Now, define a map $f: V(G) \rightarrow\{1,2, \ldots, n+1\}$ as follows. First we can label the cycle $C_{n}$ by Proposition 2.9. Then we can label the apex vertex $\mathrm{f}(\mathrm{u})=\mathrm{n}+1$.

Then we get $\left|\mathrm{e}_{\mathrm{f}}(0)-\mathrm{e}_{\mathrm{f}}(1)\right| \leq 1$.

Hence $\mathrm{G}$ is a divided square difference cordial graph.

\section{Example 3.6}

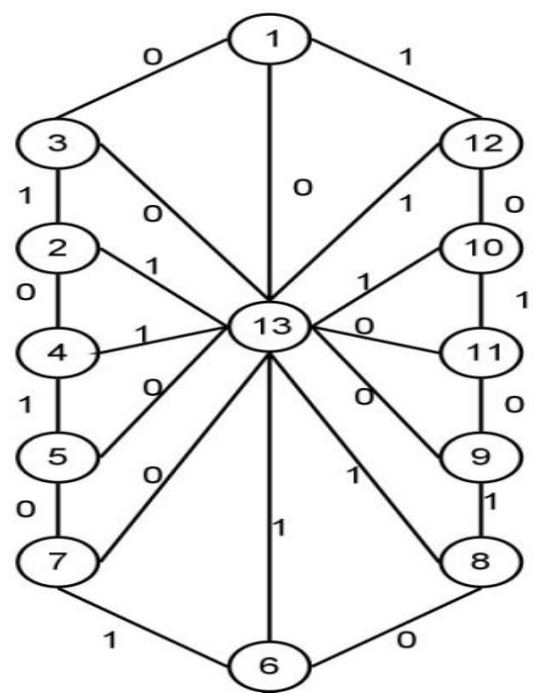

Fig. 3:Wheel Graph $\mathrm{W}_{12}$.

\section{Proposition 3.7}

The Helm graph $\mathrm{H}_{\mathrm{n}}$ is a divided square difference cordial graph except for $n=6,6+d, 6+2 d, \ldots$ where $d=4$.

\section{Proof}

Let $G$ be a Helm graph $H_{n}$. Let $x, v_{1}, v_{2}, \ldots, v_{n}, u_{1}, u_{2}, \ldots, u_{n}$ are the vertices of $H_{n}$. Here $x$ is the apex vertex, $v_{1}, v_{2}, \ldots, v_{n}$ are the vertices of the cycle $C_{n}$ and $u_{1}, u_{2}, \ldots, u_{n}$ are the pendent vertices. In this graph, $|V(G)|=2 n+1$ and $|E(G)|=3 n$.

Now, define a map $f: V(G) \rightarrow\{1,2, \ldots, 2 n+1\}$ as follows. First we can label the Wheel $\mathrm{W}_{\mathrm{n}}$ by proposition 3.5. Then we can label the pendent vertices $u_{1}, u_{2}, \ldots, u_{n}$ as $f\left(u_{k}\right)=n+k+1,1 \leq k \leq n$. Then we get

$$
e_{f}(0)-e_{f}(1)=\left\{\begin{array}{c}
0, \text { if } n \text { is even } \\
1, \text { if } n \text { is odd }
\end{array}\right.
$$

Thus, $\left|\mathrm{e}_{\mathrm{f}}(0)-\mathrm{e}_{\mathrm{f}}(1)\right| \leq 1$.

Hence $\mathrm{G}$ is a divided square difference cordial graph.

\section{Example 3.8}

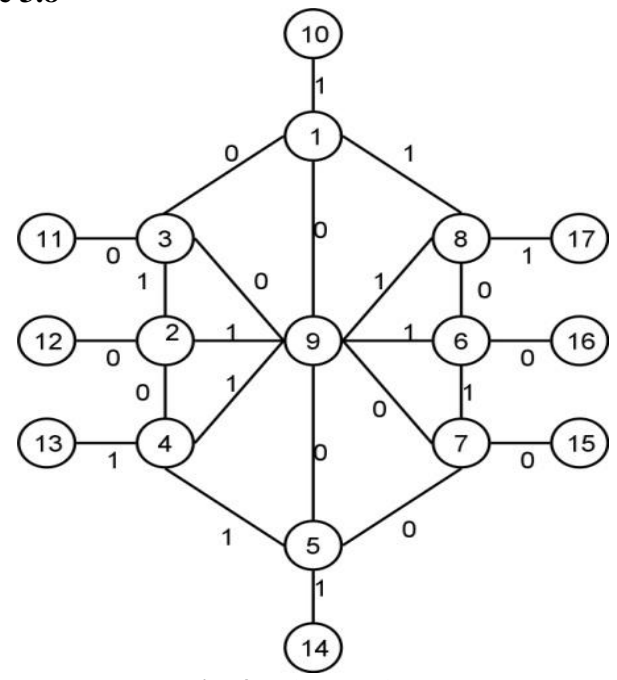

Fig. 4:Helm Graph $\mathrm{H}_{8}$

Proposition 3.9

The flower graph $\mathrm{Fl}_{\mathrm{n}}$ is a divided square difference cordial graph. Proof

Let $\mathrm{G}$ be a flower graph $\mathrm{Fl}_{\mathrm{n}}$. Let $\mathrm{x}, \mathrm{v}_{1}, \mathrm{v}_{2}, \ldots, \mathrm{v}_{\mathrm{n}}, \mathrm{u}_{1}, \mathrm{u}_{2}, \ldots, \mathrm{u}_{\mathrm{n}}$ are the vertices of $\mathrm{Fl}_{\mathrm{n}}$. Here $\mathrm{x}$ is the apex vertex, $\mathrm{v}_{1}, \mathrm{v}_{2}, \ldots, \mathrm{v}_{\mathrm{n}}$ are the vertices of the cycle $C_{n}$ and $u_{1}, u_{2}, \ldots, u_{n}$ are the pendent vertices. In this graph, $|\mathrm{V}(\mathrm{G})|=2 \mathrm{n}+1$ and $|\mathrm{E}(\mathrm{G})|=4 \mathrm{n}$. Now, define a map $f: V(G) \rightarrow\{1,2, \ldots, 2 n+1\}$ as follows. First we can label the 
Helm $\mathrm{H}_{\mathrm{n}}$ by proposition 3.7. Then join the pendent vertices to the apex vertex to get the $\mathrm{Fl}_{\mathrm{n}}$ graph.

Then we get $\left|\mathrm{e}_{\mathrm{f}}(0)-\mathrm{e}_{\mathrm{f}}(1)\right| \leq 1$.

Hence $\mathrm{G}$ is a divided square difference cordial graph.

\section{Example 3.10}

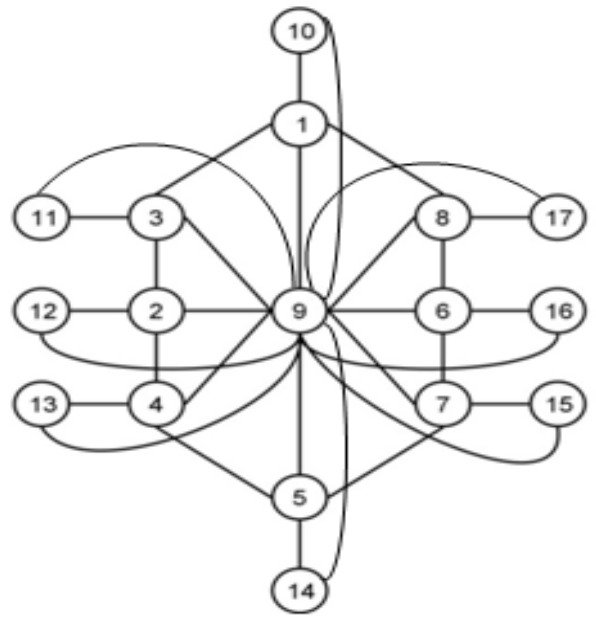

Fig. 5: Flower Graph $\mathrm{Fl}_{8}$.

\section{Proposition 3.11}

The graph $\mathrm{P}_{\mathrm{n}}+\overline{\mathrm{K}_{\mathrm{m}}}$ is a divided square difference cordial graph.

\section{Proof}

Let $G$ be a $P_{n}+\overline{K_{m}}$ graph. Let $v_{1}, v_{2}, \ldots, v_{m}$ are the vertices of $\overline{K_{m}}$ and $\mathrm{u}_{1}, \mathrm{u}_{2}, \ldots, \mathrm{u}_{\mathrm{n}}$ are the vertices of $P_{n}$.

Then $u_{1}, u_{2}, \ldots, u_{n}, v_{1}, v_{2}, \ldots, v_{m}$ are the vertices of $P_{n}+\overline{K_{m}}$. Let the edge set be

$$
E(G)=\left\{u_{i} u_{i+1}, u_{1} v_{j}, u_{n} v_{j}, 1 \leq i \leq n-1,1 \leq j \leq m\right\}
$$

In this graph, $|\mathrm{V}(\mathrm{G})|=\mathrm{m}+\mathrm{n}$ and $|\mathrm{E}(\mathrm{G})|=2 \mathrm{~m}+\mathrm{n}-1$.

Now, define a map $\mathrm{f:} V(\mathrm{G}) \rightarrow\{1,2, \ldots, \mathrm{m}+\mathrm{n}\}$ as follows.

We can label the path by Proposition 2.9 and $\overline{\mathrm{K}_{\mathrm{m}}}$ by $f\left(v_{j}\right)=n+j, 1 \leq j \leq m$.

Then we get $\left|\mathrm{e}_{\mathrm{f}}(0)-\mathrm{e}_{\mathrm{f}}(1)\right| \leq 1$.

Hence $\mathrm{G}$ is a divided square difference cordial graph.

\section{Example 3.12}

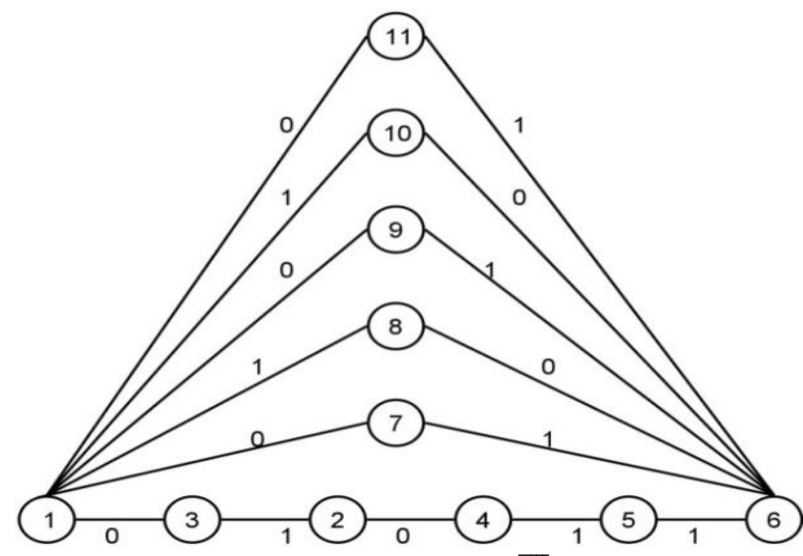

Fig. 6:Graph $\mathrm{P}_{6}+\overline{\mathrm{K}_{5}}$

\section{Proposition 3.13}

The graph $\left(\overline{\mathrm{K}_{m}} \cup \mathrm{P}_{\mathrm{n}}\right)+2 \mathrm{~K}_{1}$ is a divided square difference cordial graph.

Proof

Let $\mathrm{G}$ be a $\left(\overline{\mathrm{K}_{\mathrm{m}}} \cup \mathrm{P}_{\mathrm{n}}\right)+2 \mathrm{~K}_{1}$ graph.

Let $\mathrm{x}, \mathrm{y}$ are the vertices of $2 \mathrm{~K}_{1}, \mathrm{v}_{1}, \mathrm{v}_{2}, \ldots, \mathrm{v}_{\mathrm{m}}$ are the vertices of $\overline{K_{m}}$ and $u_{1}, u_{2}, \ldots, u_{n}$ are the vertices of $P_{n}$.

Then $\mathrm{x}, \mathrm{y}, \mathrm{u}_{1}, \mathrm{u}_{2}, \ldots, \mathrm{u}_{\mathrm{n}}, \mathrm{v}_{1}, \mathrm{v}_{2}, \ldots, \mathrm{v}_{\mathrm{m}}$ are the vertices of $\left(\overline{\mathrm{K}_{\mathrm{m}}} \cup \mathrm{P}_{\mathrm{n}}\right)+2 \mathrm{~K}_{1}$.

In this graph, $|\mathrm{V}(\mathrm{G})|=\mathrm{m}+\mathrm{n}+2$ and $|\mathrm{E}(\mathrm{G})|=2 \mathrm{~m}+3 \mathrm{n}-1$.
Now, define a map $\mathrm{f}: \mathrm{V}(\mathrm{G}) \rightarrow\{1,2, \ldots, \mathrm{m}+\mathrm{n}+2\}$. We can construct the path $\mathrm{P}_{\mathrm{n}}$ by Proposition 2.9, label $\overline{\mathrm{K}_{\mathrm{m}}}$ by $f\left(v_{j}\right)=n+j, 1 \leq j \leq m$ and $2 K_{1}$ by $f(x)=m+n+1$, $\mathrm{f}(\mathrm{y})=\mathrm{m}+\mathrm{n}+2$.

Then we get $\left|\mathrm{e}_{\mathrm{f}}(0)-\mathrm{e}_{\mathrm{f}}(1)\right| \leq 1$.

Hence $\mathrm{G}$ is a divided square difference cordial graph.

\section{Example 3.14}

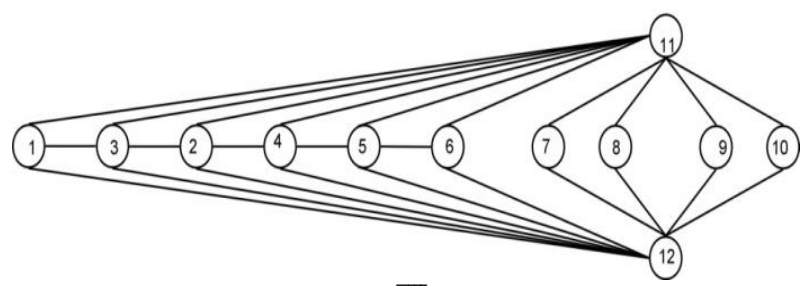

Fig. 7: $\operatorname{Graph}\left(\overline{\mathrm{K}_{4}} \cup \mathrm{P}_{6}\right)+2 \mathrm{~K}_{1}$

\section{Proposition 3.15}

Bistar $B_{m, m}$ is a divided square difference cordial graph.

\section{Proof}

Let $\mathrm{G}$ be a $B_{m, m}$ graph.

Let $u_{1}, u_{2}, \ldots, u_{m}$ and $v_{1}, v_{2}, \ldots, v_{m}$ are the vertices of each copy of $K_{1, m}$ with the apex vertex $x$ and $y$.

In this graph, $|V(G)|=2 m+2$ and $|E(G)|=2 m+1$.

Let the edge set be $E(G)=\left\{x y, y v_{i}, x u_{i}, 1 \leq i \leq m\right\}$.

Now, define a map $f: V(G) \rightarrow\{1,2, \ldots, 2 m+2\}$ as follows.

We can label the vertices by taking,

$$
\begin{gathered}
f(x)=1, f(y)=m+2, f\left(u_{i}\right)=i, 2 \leq i \leq m+1 \\
f\left(v_{i}\right)=m+2+i, 1 \leq i \leq m
\end{gathered}
$$

Then we get $\left|e_{f}(0)-e_{f}(1)\right| \leq 1$.

Hence $\mathrm{G}$ is a divided square difference cordial graph.

Example 3.16

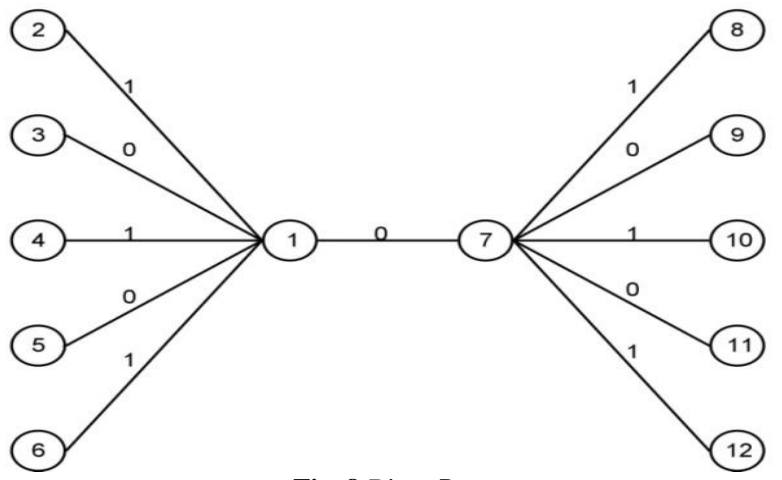

Fig. 8:Bistar $B_{5,5}$

\section{Conclusion}

In this paper, the concepts of divided square difference cordial labeling behaviour of Jewel graph, $C_{n-2}+K_{2}$, Wheel graph, Helm graph, Flower graph, $P_{n}+\overline{K_{m}}, \overline{K_{m}} \cup P_{n}+2 K_{1}$, Bistar $B_{m, m}$ were discussed. This work can be extended to other type of graphs such as neutrosophic graphs, fuzzy graphs, intuitionistic fuzzy graphs.

\section{Acknowledgement}

The authors are highly thankful to the anonymous referees for constructive suggestions and comments. Also thankful to Dr.R.Dhavaseelan for his valuable feedback and comments. 


\section{References}

[1] A.Alfred Leo, R.Vikramaprasad and R.Dhavaseelan; Divided square difference cordial labeling graphs, International journal of Mechanical Engineering and Technology, 9 (1), (Jan 2018), pp. 1137 - 1144

[2] Bondy J.A and Murty.U.S.R, Graph theory and applications, North Holland, New York, (1976).https://doi.org/10.1007/978-1-34903521-2.

[3] I. Cahit, "Cordial graphs: a weaker version of graceful and harmonious graphs," Ars Combinatoria, 23(1987), pp. 201-207.

[4] David M. Burton, Elementary Number Theory, Second Edition, Wm. C. Brown Company Publishers, (1980).

[5] R.Dhavaseelan, R.Vikramaprasad and S.Abhirami; A New Notions of Cordial Labeling Graphs, Global Journal of Pure and Applied Mathematics, 11 (4) (2015), pp.1767 - 1774.

[6] J. A. Gallian, A dynamic survey of graph labeling, Electronic $J$. Combin. 15 (2008), DS6, pp.1 - 190.

[7] F. Harary, Graph theory, Addison-Wesley, Reading, MA. (1969).https://doi.org/10.21236/AD0705364.

[8] P. Lawrence Rozario Raj and R. Valli, Some new families of divisor cordial graphs, International Journal of Mathematics Trends and Technology, 7(2), (2014), pp.94102.https://doi.org/10.14445/22315373/IJMTT-V7P512.

[9] A. Rosa, on certain valuations of the vertices of a graph, Theory of Graphs (Internat. Symposium, Rome, July 1966), Gordon and Breach, N. Y. and Dunod Paris, (1967), pp.349 - 355.

[10] Rosen, Kenneth H, Discrete Mathematics and its applications, $7^{\text {th }}$ edition, McGraw-Hill, (2011), pp. 655.

[11] S.K.Vaidya and N.H.Shah, Further results on divisor cordial labeling, Annals of Pure and Applied Mathematics, 14(2), (2013), pp. 150-159. 